\title{
Established and innovative surgical techniques for the treatment of benign subglottic stenosis
}

\author{
Matthias Evermann ${ }^{1}$, Thomas Schweiger ${ }^{1}$, Imme Roesner ${ }^{2}$, Doris-Maria Denk-Linnert ${ }^{2}$, \\ Walter Klepetko ${ }^{1}$, Konrad Hoetzenecker ${ }^{1}$ \\ ${ }^{1}$ Division of Thoracic Surgery, Department of Surgery, ${ }^{2}$ Division of Phoniatrics and Logopedics, Department of Otolaryngology, Medical University \\ of Vienna, Vienna, Austria \\ Contributions: (I) Conception and design: All authors; (II) Administrative support: None; (III) Provision of study materials or patients: None; \\ (IV) Collection and assembly of data: All authors; (V) Data analysis and interpretation: None; (VI) Manuscript writing: All authors; (VII) Final \\ approval of manuscript: All authors. \\ Correspondence to: Konrad Hoetzenecker, MD, PhD. Division of Thoracic Surgery, Department of Surgery, Medical University of Vienna, \\ Waehringer Guertel 18-20, A-1090 Vienna, Austria. Email: konrad.hoetzenecker@meduniwien.ac.at.
}

\begin{abstract}
Surgical treatment of benign subglottic stenoses can be challenging. It requires the close cooperation of an experienced team that includes various specialist disciplines. The treatment success will be evaluated with an extensive documentation of voice quality, lung function and swallowing function. The stenosis has to be analyzed in terms of its etiology, severity and pretreatment. Endoscopic removal of the stenotic tissue often leads to good short-term results. However, the proportion of re-stenoses is very high, which are often even more severe. Long-term treatment success can often only be achieved by surgical resection. The surgical technique used must be strictly adapted to the individual stenosis. In principle, a distinction can be made between classic cricotracheal resections and those that receive an expanded operative component. Particularly in the case of high-grade side-to-side stenoses, complex reconstruction with cartilage graft may be necessary. It is important not just to restore the airway flow. Maintaining the vocal function is an equally important treatment goal. Experienced centers can achieve very satisfactory long-term results with regard to functional outcome and voice quality.
\end{abstract}

Keywords: Laryngotracheal surgery; benign subglottic stenosis; single-stage laryngotracheal reconstruction

Submitted Feb 10, 2020. Accepted for publication Feb 28, 2020.

doi: $10.21037 /$ tcr.2020.02.76

View this article at: http://dx.doi.org/10.21037/tcr.2020.02.76

\section{Background}

The optimal treatment of subglottic stenoses requires an experienced team, routinely dealing with airway pathologies. Various surgical techniques are now available to even offer complex patient acceptable long-term solutions. A close collaboration between surgeons, otorhinolaryngologists, phoniatrists, pulmonologists and anesthesiologists is essential and pre- and post-operative care of this interdisciplinary team is pivotal. The preoperative examination includes a full endoscopic documentation of the pathology. Moreover, a measurement of the voice quality, lung function and swallowing function belongs to the standard assessment before and after surgery. These measures are of crucial importance in order to evaluate a success of an intervention. The goal of a laryngotracheal procedure is not only to restore sufficient airway width but maintaining laryngeal function is at least equally important as it has a strong impact on patients' quality of life. A successful repair of a subglottic stenosis requires precise knowledge of the anatomical peculiarities of the larynx. Depending on the etiology and the severity of the stenosis, a surgical procedure tailored to the individual patient has to be found. For this purpose, an exact patient medical history is required that identifies possible causes such as previous intubation, endoscopic treatments or tracheostomy. Usually, 

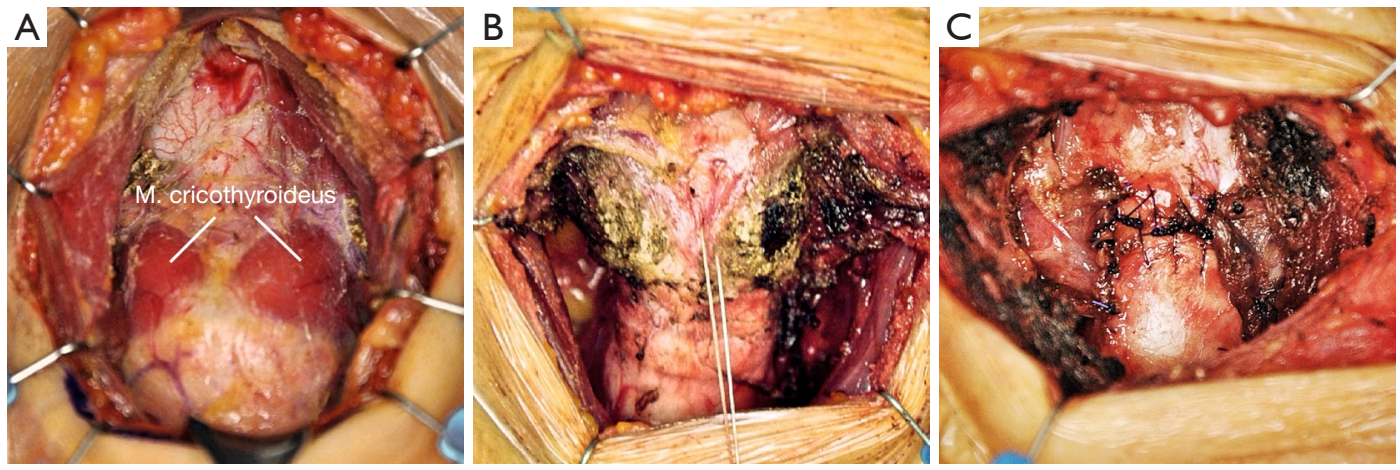

Figure 1 The laryngotracheal junction is exposed (A). The cricothyroid muscles are detached from the cricoid (B) and can be reinserted at the end of the procedure $(\mathrm{C})$.

patients having received multiple pre-treatments require more complex surgical procedures (1). An active systematic or autoimmune disease, as well as a malignant disease must also be excluded (2).

\section{Assessment}

A prerequisite for the planning of the surgical procedure is a precise endoscopic assessment of the stenosis. The severity and extent of the narrowing is documented. Usually, the Cotton-Myer grade is used to describe the residual lumen (3). The proximity of the scar tissue to the vocal fold is determined and an involvement of the vocal chords or the arytenoid cartilages by the scar tissue is documented. The length of the stenosis and the entire trachea is also measured (4).

\section{Surgical techniques}

The first publications on the treatment of subglottic stenoses reach back to Pearson et al. (5) (1975) and Grillo (6) (1982) and subglottic surgery has evolved since then. In general, three basic surgical techniques can be distinguished. The standard cricotracheal resection is the technique of choice for scar tissue primarily involving the anterior subglottic area. If other parts of the subglottis (such as in the lateral area or the posterior cricoid plate) are affected, a cricotracheal resection has to be extended by additive techniques in order to remove the entire scar tissue. An extended cricotracheal resection includes a dorsal mucosectomy, a lateral cricoplasty and/or a partial anterior split of the thyroid. If these techniques still do not result in satisfactory glottic width, laryngotracheal reconstruction with rib cartilage interposition has to be performed. This results in an enlargement of the subglottic area, especially in patients with significant side-to-side narrowing of the subglottis.

\section{Preparation}

The patient is prepared in the supine position with the neck overextended. For ventilation, either a laryngeal mask or a preexisting tracheostomy is used. The cervical incision is performed at the level of the cricoid. This is followed by the preparation of the underlying platysma, fat and division of the strap muscles in the midline. When the deeper layers are reached, a retractor ring facilitates the exposure of the surgical field. Larynx and trachea are carefully prepared and visualized.

A traction suture in the anterior cricoid arch is useful to retract the larynx and trachea during preparation from the surrounding tissue. The cricothyroid muscles (Figure 1A) are carefully detached from the cricoid (Figure 1B). The preservation and refixation of these muscles at the end of the procedure ensures an improved postoperative outcome (Figure 1C) (7).

\section{Standard cricotracheal resection}

The trachea is divided distal to the stenosis and two lateral traction sutures are placed. Cross-table ventilation by a sterile endotracheal tube is initiated. The cricoid arch is now separated along the cricothyroid membrane and removed with a bilateral oblique cut through the cartilage to the dorso-caudal direction (Figure 2A,B,C).

In anterior type stenosis, the entire scar tissue is removed together with the cricoid arch and healthy mucosa should 

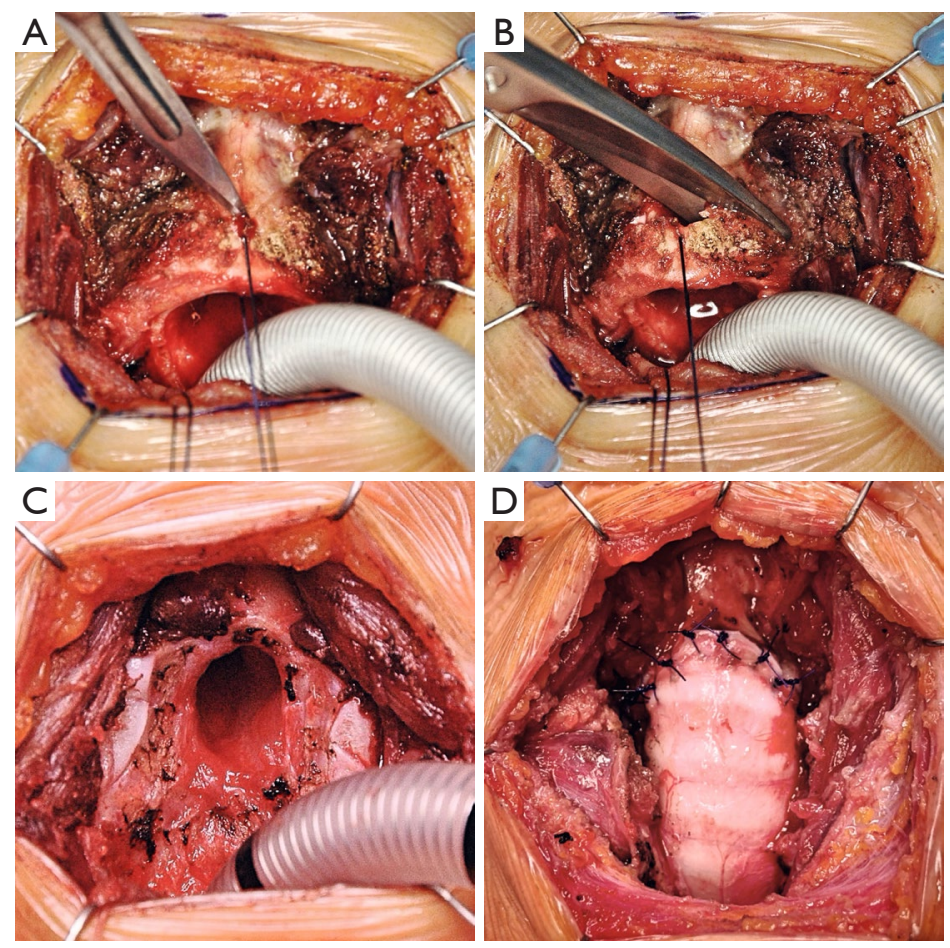

Figure 2 The cricothyroid membrane is incised using a scalpel (A) and the removal of the anterior cricoid arch is completed using heavy scissors (B). Intraoperative aspect after resection of the cricoid arch is shown in (C). A thyro-tracheal end-to-end anastomosis is performed using 4-0 PDS single stitches for the anterior and lateral portions of the anastomosis (D).

have been reached proximally and distally. The distal trachea is now prepared so that it can be adapted to the rest of the cricoid. Dorsally, the cricoid plate is anastomosed with the trachea using a 5-0 PDS running suture. Single 4-0 PDS sutures are then placed at the lateral and anterior portions of the anastomosis. This is performed in intermittent apnea phases. The neck extension is reduced and nerve hooks are used to adapt the running suture of the back wall. Finally, the sutures are tied down (Figure 2D).

After the anastomosis has been carefully closed, ventilation can be resumed via the laryngeal mask. A final bronchoscopy is done to examine the anastomosis. After inserting a Redon drainage, the wound is closed layer by layer. To reduce the tension, the head is kept in a head cradle during the first 2-3 postoperative days.

\section{Extended cricotracheal resection}

If the scar tissue also affects the lateral or dorsal parts of the subglottis, standard cricotracheal resection is usually not sufficient to reach healthy mucosa at the resection margins. Therefore, cricotracheal resection has to be combined with additive procedures.

Dorsal mucosectomy is usually necessary for subglottic stenoses affecting the mucosa on the cricoid plate. A U-shaped incision in made on the dorsal mucosa reaching cranially until healthy mucosa is reached. The scar tissue can easily be separated from the perichondrium of the cricoid plate using a fine beaver knife (Figure $3 A, B)(8)$.

The denuded cartilage is covered with a dorsal flap of the distal tracheal mucosa. The mucosal flap is sewn to the mucosa of the glottis with a running 5-0 or 6-0 PDS suture (Figure 3C). For the sutures of the lateral and anterior part of the anastomosis 4-0 PDS is used and the anastomosis is closed with gradual adaptation (Figure 3D,E).

The lateral cricoplasty is particularly appropriate for subglottic stenoses with moderate side-to-side narrowing. This method was first described by Liberman and colleagues (9).

The healthy mucosa is carefully separated laterally from the pathologically thickened submucosa. The submucosa is reduced by a wedge while the healthy mucosa is preserved. The mucosa is then laterally tacked to the cartilage using two to three 6-0 PDS stiches (Figure 4). 

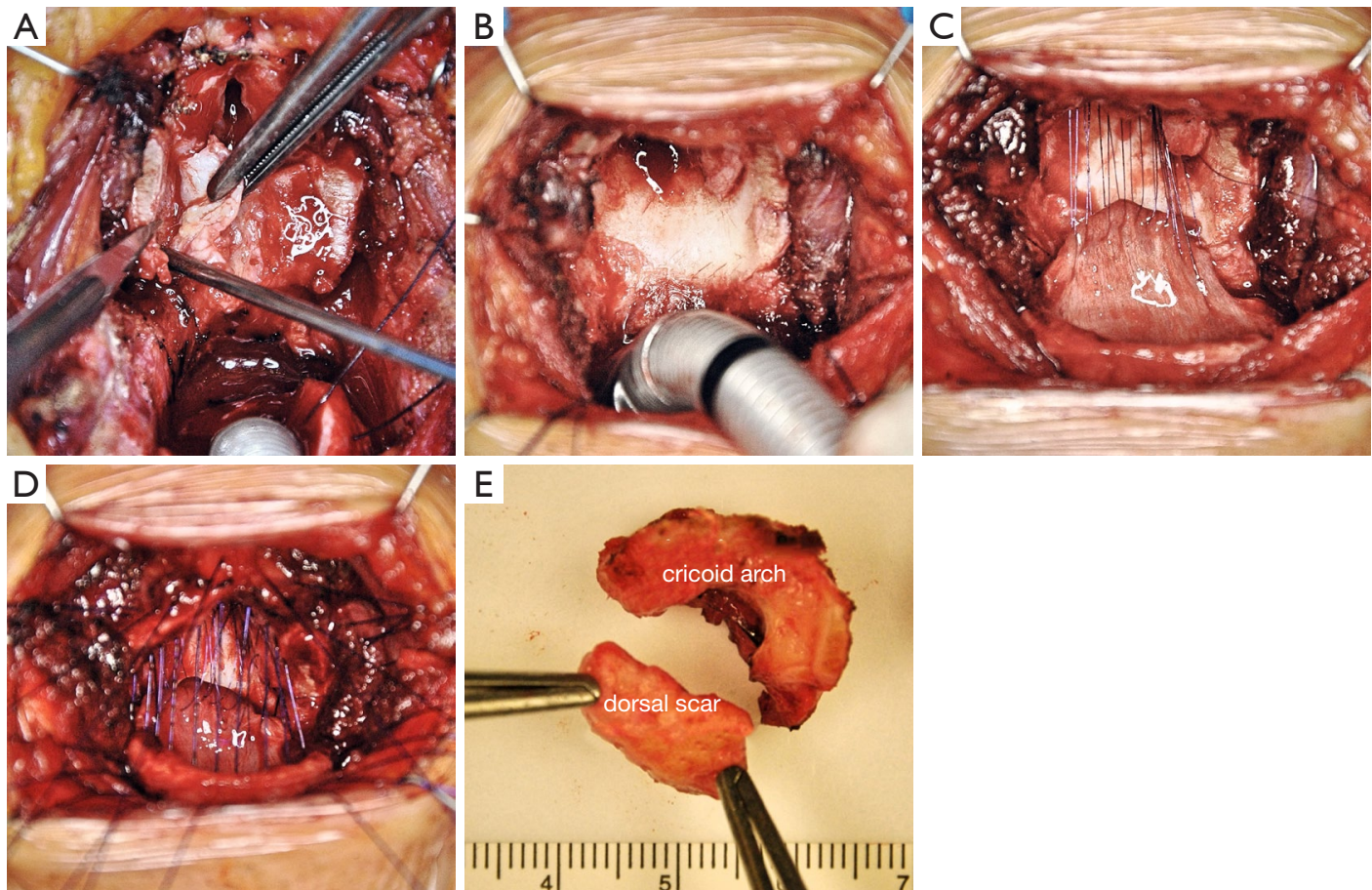

Figure 3 A scalpel is used to peel off the dorsal scar from the perichondrium of the cricoid plate (A). After completion of the dorsal mucosectomy, a sufficient lumen of the subglottis is achieved (B). Afterwards the cricoid plate is covered by a mucosal flap raised from the distal trachea (C) and anastomosis is completed (D). The surgical specimen consists of the cricoid arch and the dorsal mucosa (E).
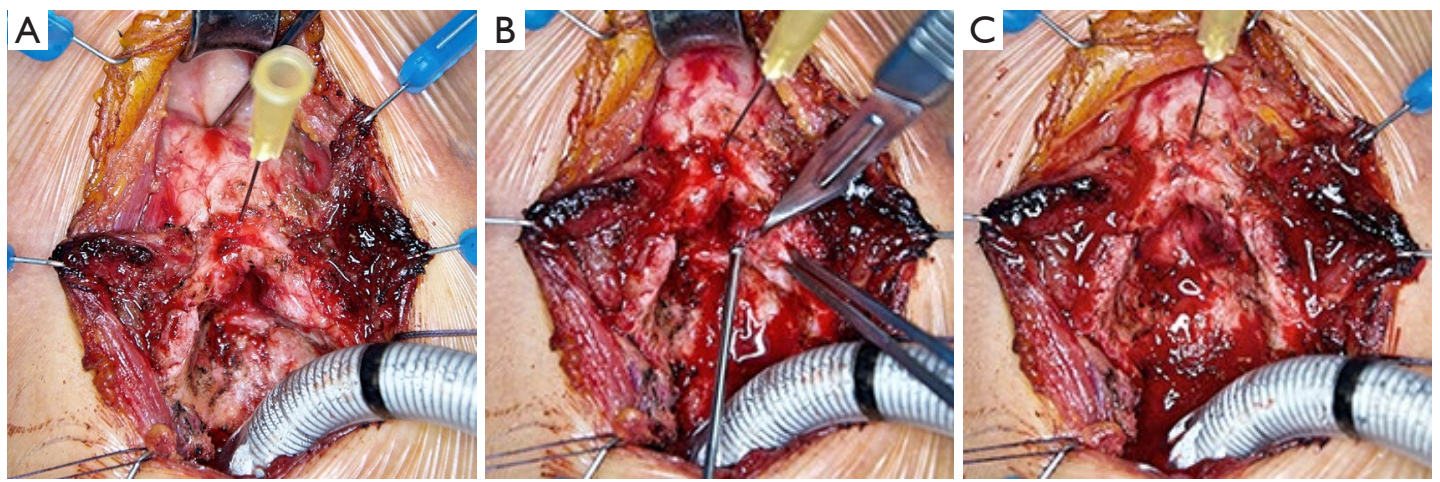

Figure 4 Subglottic stenosis with significant lateral submucosal scar formations is shown in (A). A lateral cricoplasty using a scalpel is performed (B). After re-adaption of the lateral mucosa, a significant increase in the subglottic lumen is reached (C).

\section{Single-stage laryngotracheal reconstruction}

In some complex cases a sufficient subglottic width cannot be achieved by mere resection. This is particularly true in cases with a side-to-side stenosis at the glottosubglottic level. In these cases, a glottic enlargement has to be performed using a rib cartilage interposition. The development of the adult laryngeal reconstruction goes back to Couraud and colleagues. In contrast to the Couraud technique, the modified technique described by the Vienna airway group does not require postoperative stenting (10).

After removing the cricoid arch, the anterior thyroid is either split completely or only partially. If necessary, a mucosectomy of the scar tissue is performed on the cricoid plate. The cricoid plate is then completely split along its 

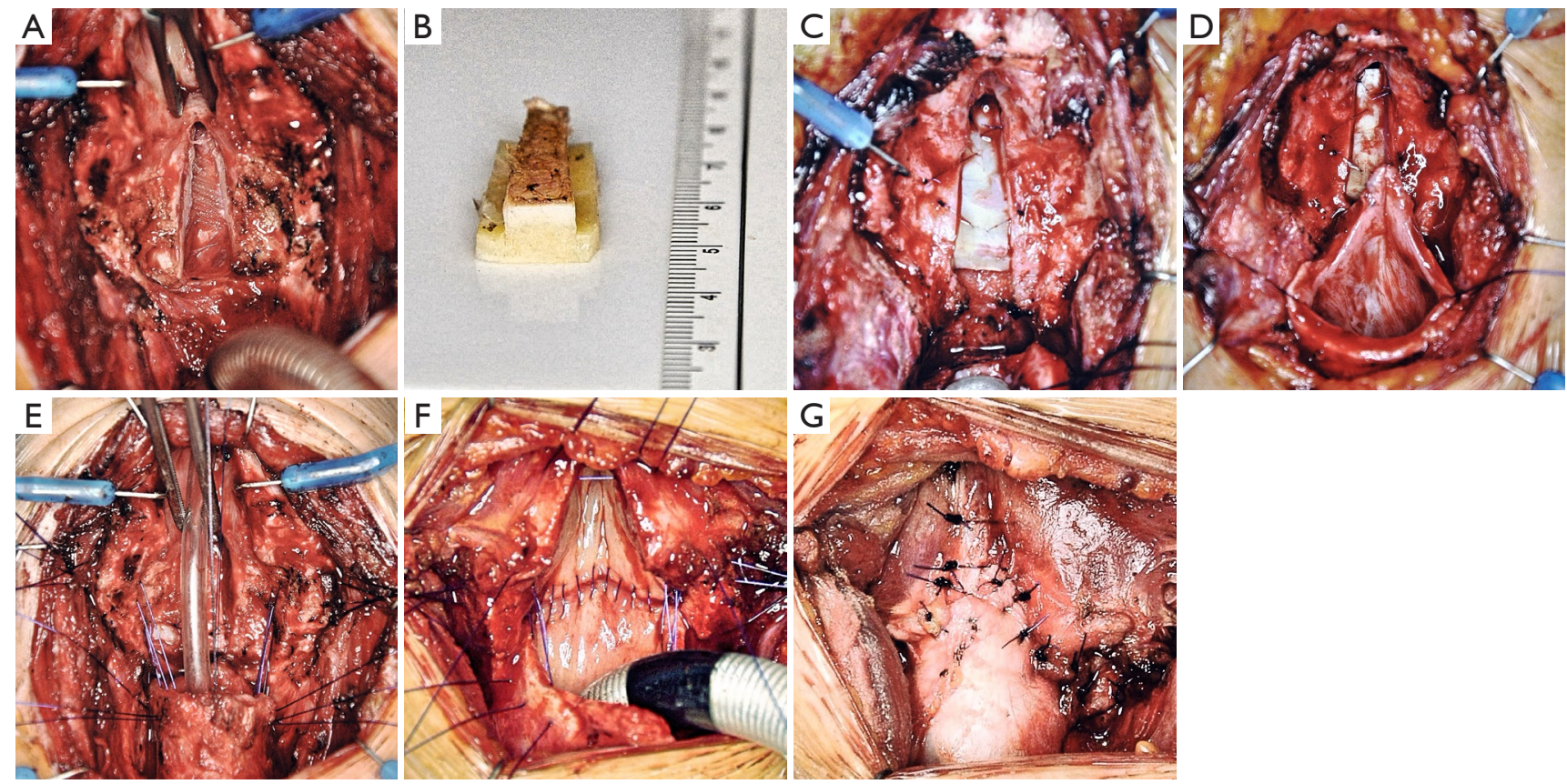

Figure 5 Intraoperative aspect after complete anterior and posterior split of the larynx is shown in (A). The rib cartilage graft is prepared to fit into the posterior laryngeal split (B). Although sufficient stability is reached by the lateral flanges, the cartilage graft is secured with four 6-0 stitches (C). The dorsal reconstruction is covered with a liberal mucosa flap raised from the distal trachea (D). During reconstruction, Jet ventilation facilitates exposure and manipulation in the surgical field (E). The anastomosis is completed by a single-running suture for the posterior aspect, the anterior and lateral portions are anastomosed using 4-0 PDS single stitches (F). A wedge raised from the anterior tracheal wall is used to increase the diameter of the subglottis by partial interpositioning into the anterior laryngeal split (G).

midline (Figure $5 A$ ). The tissue behind the cricoid plate is carefully mobilized to create a little pocket for the cartilage interposition. An approximately $3 \mathrm{~cm}$ large rib cartilage graft is harvested from the costal arch near the sternum through a second incision. Special care has to be taken not to open the pleural cavity. The cartilage is tailored using a scalpel (Figure 5B). Two flanges laterally will later prevent the cartilage graft from dislocation. Additionally, four 6-0 prolene single stitches are used to secure the graft in its correct position (Figure 5C).

A dorsal mucosal flap is prepared from the distal trachea (Figure 5D). The trachea is modeled anteriorly in a V-shape to be inserted into the anterior thyroid split. If available, ventilation can be switched to a jet ventilator during laryngeal reconstruction and anastomosis, which significantly facilitates surgical exposure (Figure 5E).

The cartilage interposition is carefully closed with the dorsal mucosal flap (Figure 5F).

The anterior split is also precisely readapted and anastomosed to the anterior tracheal wedge (Figure $5 G$ ).

Ventilation can be changed back to the laryngeal mask and bronchoscopy is performed to assess the anastomosis. If significant glottic swelling occurs, a temporary minitracheostoma (size 5 or 6 ) can be inserted distal to the anastomosis. Usually, it can be removed after 3-4 days when the glottic edema has resolved.

\section{Conclusions}

In experienced centers, the surgical treatment of benign subglottic stenosis leads to excellent outcomes $(11,12)$. Long-term patency of the airways and maintenance of laryngeal function can be achieved (13). Both factors are critical to the quality of life and patient satisfaction after the procedure (14). Therefore, patients with subglottic stenoses should be referred to specialized centers with interdisciplinary teams experienced in surgical repair of subglottic stenosis.

\section{Acknowledgments}

Funding: None. 


\section{Footnote}

Provenance and Peer Review: This article was commissioned by the editorial office, Translational Cancer Research for the series "Recent Developments in Benign Tracheal Stenosis". The article has undergone external peer review.

Conflicts of Interest: All authors have completed the ICMJE uniform disclosure form (available at http:// dx.doi.org/10.21037/tcr.2020.02.76). The series "Recent Developments in Benign Tracheal Stenosis" was commissioned by the editorial office without any funding or sponsorship. KH served as the unpaid Guest Editor for the series. The authors have no other conflicts of interest to declare.

Ethical Statement: The authors are accountable for all aspects of the work in ensuring that questions related to the accuracy or integrity of any part of the work are appropriately investigated and resolved.

Open Access Statement: This is an Open Access article distributed in accordance with the Creative Commons Attribution-NonCommercial-NoDerivs 4.0 International License (CC BY-NC-ND 4.0), which permits the noncommercial replication and distribution of the article with the strict proviso that no changes or edits are made and the original work is properly cited (including links to both the formal publication through the relevant DOI and the license). See: https://creativecommons.org/licenses/by-nc-nd/4.0/.

\section{References}

1. Wright CD, Grillo HC, Wain JC, et al. Anastomotic complications after tracheal resection: prognostic factors and management. J Thorac Cardiovasc Surg 2004;128:731-9.

2. Gelbard A, Francis DO, Sandulache VC, et al. Causes and consequences of adult laryngotracheal stenosis. Laryngoscope 2015;125:1137-43.

3. Myer CM 3rd, O'Connor DM, Cotton RT. Proposed

Cite this article as: Evermann M, Schweiger T, Roesner I, Denk-Linnert DM, Klepetko W, Hoetzenecker K. Established and innovative surgical techniques for the treatment of benign subglottic stenosis. Transl Cancer Res 2020;9(3):2136-2141. doi: $10.21037 /$ tcr.2020.02.76 grading system for subglottic stenosis based on endotracheal tube sizes. Ann Otol Rhinol Laryngol 1994;103:319-23.

4. Filauro M, Mazzola F, Missale F, et al. Endoscopic Preoperative Assessment, Classification of Stenosis, Decision-Making. Front Pediatr 2020;7:532.

5. Pearson FG, Cooper JD, Nelems JM, et al. Primary tracheal anastomosis after resection of the cricoid cartilage with preservation of recurrent laryngeal nerves. J Thorac Cardiovasc Surg 1975;70:806-16.

6. Grillo HC. Primary reconstruction of airway after resection of subglottic laryngeal and upper tracheal stenosis. Ann Thorac Surg 1982;33:3-18.

7. Couraud L, Hafez A, Velly JF, et al. Current reconstructive management of subglottic stenosis of the larynx with reference to sixty consecutively treated cases. Thorac Cardiovasc Surg 1985;33:263-7.

8. Mathisen DJ. Subglottic tracheal resection. Oper Tech Thorac Cardiovasc Surg 1998;3:142-53.

9. Liberman M, Mathisen DJ. Tailored cricoplasty: an improved modification for reconstruction in subglottic tracheal stenosis. J Thorac Cardiovasc Surg 2009;137:5738; discussion 578-9.

10. Hoetzenecker K, Schweiger T, Roesner I, et al. A modified technique of laryngotracheal reconstruction without the need for prolonged postoperative stenting. J Thorac Cardiovasc Surg 2016;152:1008-17.

11. Ashiku SK, Kuzucu A, Grillo HC, et al. Idiopathic laryngotracheal stenosis: effective definitive treatment with laryngotracheal resection. J Thorac Cardiovasc Surg 2004;127:99-107.

12. Hseu AF, Benninger MS, Haffey TM, et al. Subglottic stenosis: a ten-year review of treatment outcomes. Laryngoscope 2014;124:736-41.

13. Monnier P. Partial Cricotracheal Resection and Extended Cricotracheal Resection for Pediatric Laryngotracheal Stenosis. Thorac Surg Clin 2018;28:177-87.

14. Gelbard A, Anderson C, Berry LD, et al. Comparative Treatment Outcomes for Patients With Idiopathic Subglottic Stenosis. JAMA Otolaryngol Head Neck Surg 2019:1-10. [Epub ahead of print]. 